\title{
BREVE HISTORIA DEL ORIGEN DEL TABACO EN AMÉRICA Y SU DIFUSIÓN EN EUROPA

\author{
Julio R. Olivera
}

Rodrigo de Xeres y Luis de Torres, comisionados por Colón partieron de Guanahaní (San Salvador) para explorar tierra firme en 1492, internándose en la selva centroamericana. Pudieron mirar un espectáculo nunca antes contemplado, que los nativos de la isla sorbían fuego y arrojaban humo por la boca y la nariz, sin causarles malestar alguno aparentemente ${ }^{1}$. Los indígenas llamaban a esta planta "Coviva", "Cojiva" o "Cohiva", y los indios de América Septentrional lo llamaban "Petum"3. En el Perú lo llamaban "Sayri"'. En Martinica "Macuba" y "Yetl" al norte del Brasil $1^{5}$. Los aborígenes de las islas occidentales la llamaban "Yoli" y "Shayli" en varias comunidades del Norte de Ancash.

El nombre de tabaco provendría según unos del instrumento en forma de "Y" que los nativos cubanos utilizaban para embriagarse con las exhalaciones del humo. Este aparato fue

1 DE LA FUENTE, E. Zamora. (1959). El Tabaco y su cultivo. México. Cf. RAMOS PERES, Demetrio. (1947). Historia de la Colonización española en América. pp. 194-195 Madrid.

2 U. T. E. H.A. (1953). Diccionario Enciclopédico T. IX. México.

3 JHON RAIMOND, Ed. Tobacco-Dictionary, Copyright by Philosophical Library. N.Y.

4 DE LA VEGA, Inca Garcilaso. (1943). Comentarios Reales de los Incas. T. II, L. V, p. 189. B.A.

5 EBRO, Juan de. El Tabaco, su cultivo e Historia. Su influencia en el organismo. conocido por los españoles con el nombre de "tabaco". Posiblemente su nombre se le daba a la provincia de Tabasco, lugar de la Nueva España y no al de la isla Tabago de las Antillas como pretenden algunos autores ${ }^{6}$.

Los nativos americanos en su mayor parte fumaban cigarros envueltos en hojas de maíz o de palmera, además de usarlo en puros, en pipas, masticado y en forma de rapé como notaremos en el cuadro tentativo de secuencias ecológicas.

El uso de esta solanácea, nos narran los cronistas, se empleaba en los ritos y hechicerías. Cobo dice que los Sacerdotes eran a la vez confesores, médicos y hechiceros ${ }^{7}$. Molina el Cuzqueño ${ }^{8}$ refiere a los Conasocas que eran curanderos y conocedores de todo tipo de hierbas incluyendo las tóxicas. Los Yacaraes que empleaban ciertas hornillas con muchos agujeros por los que soplaban con canutos de cobre y plata; y según salía el fuego por estos agujeros se respondía a lo consultado. (Adivinos del

6 DE LA FUENTE, E. Zamora. Ob. Cit.

7 COBO, P. Bernabé. (1956). Historia del Nuevo Mundo. Bib. de Autores españoles. Madrid.

8 MOLINA, Cristóbal de (el Cuzqueño). (1916). Relación de las Fábulas y Ritos de los Incas. Colección de libros y documentos referentes a la Historia del Perú. T. I, Ed. H.H. Urteaga y C. A. Romero. Lima, Sanmarti\&Cía. 
pueblo de Huaro-Cuzco). Los Ayartapuc, que hacían preguntas a los muertos y los Hechiceros que con tóxicos adormecían a los hombres, los compelían a que entre sueños respondieran a sus preguntas. Y los Huirapircos, que adivinaban por el humo, conocidos por Montesinos ${ }^{9}$ como los Sayrapircos. Nos refiere que para conquistar el amor, el mago ingería una cantidad de coca, tabaco verde y canela, después de haber tomado alguna prenda de la persona que se trataba de conquistar, luego cantaba invocando a los espíritus y con las cosas que ha ofrecido a la "huaca de los amores", lo entierra en una olla y cerca de dos ríos, a lo que denomina "Tincuc". Los indios creían que con este procedimiento en tanto surta efecto ninguna persona puede apartarse del que ama.

Podríamos ubicar el origen peruano de esta planta, dentro del periodo Arcaico y final del Formativo, por haber encontrado evidencias de su uso, aunque no probablemente en proceso de domesticación. Sin duda en la etapa salvaje seguida de la experiencia del recolector, "su aparición no marca el establecimiento de la barbarie". Sin embargo, su desarrollo lo consideraríamos a nivel de estos estadios. Muchas plantas han sido recuperadas en los establecimientos arqueológicos. "Las técnicas más o menos precisas de cronologización, como el Radio Carbono, han permitido la ubicación temporal de las muestras y finalmente, las asociaciones que se han recuperado con las muestras permiten su ubicación dentro de un contexto cultural dado... el análisis del material, por otro lado, parte de la separación de las plantas en dos grandes grupos: Cultivadas y Silvestres"10. El tabaco no se llegó a domesticar ni en el Arcaico ni en el Formativo.

Alden Mason dentro del periodo Cultista (850-500 a.C.) incluye el periodo Guañape (3200-1, 250 a.C.) donde se encuentran tubos para tabaco en polvo y cuencas de hueso, aparentemente para uso de rapé.

Frederic Engel, además de encontrarlos en

9 MONTESINOS, Fernando. (1882). Memorias Antiguas Historiales del Perú. 1ra. Ed. Madrid.

10 LUMBRERAS, Luis Guillermo. (1967). "La evidencia etnobotánica en el análisis del tránsito de la economía recolectora a la economía productora de alimentos". Perú Indígena № 36. Lima. el precerámico, hablando del empleo de la madera en el sitio de Asia (Lima-Perú) nos dice de tabletas y tubos para rapé. La tableta es esculpida dentro de una planchera tallada de $5 \mathrm{~mm}$ de largo y $10 \mathrm{~mm}$ de profundidad. Mide 132 x 82 x $15 \mathrm{~mm}$. El tubo es de $28 \mathrm{~mm}$ de largo y es de madera dura probablemente ahuecado artificialmente en todos sus lados. Estas piezas presentan una analogía con las encontradas por Bird sobre la costa chilena. Posteriormente nos refiere que también aparecen asociados en los horizontes con cerámica ${ }^{11}$.

No precisamos históricamente el uso de este alcaloide. Lo encontramos difundido en diferentes islas americanas del Atlántico, igualmente en el Norte, Centro y Sudamérica, además ya en Australia se reproducían en forma espontánea las especies Nicotinum suaveolens y sus variedades, que como refiere Holmes ${ }^{12}$ adoptaban formas enormes que medían cerca de cuatro metros.

Los botánicos reducen a una sola especie el tabaco usual o Nicotina tabacum, cuyas características son: lámina fina, colores claros y sabor agradable. Otra especie del tabaco es la Nicotiana rústica, silvestres, usada por los aborígenes peruanos y conocida tanto en la sierra como en la costa. Tales plantas se encontraron usadas para la momificación de cadáveres, sin dudar que por haberse descubierto que la descomposición de las hojas sobre la carne, impedían la formación de fauna cadavérica y en consecuencia su descomposición o putrefacción. La Nicotiana rústica fue cultivada por los indios norteamericanos, pero por su mala calidad fue desechada por la colonización inglesa, comenzando a importar semillas de Venezuela y Cuba.

El padre Labat subdivide esta especie en Tabaco de Verina, Tabac Des Amazones, Tabac Alanque y Legran Petun de hojas largas, carnuda y bellosa ${ }^{13}$.

11 MASON, J. Alden. (1962). Las Antiguas Culturas del Perú. Pp. 42, 50, 143. México. Cf. ENGEL, Frederic. (1957), "Sites et établissements sans céramique de la Cóte peruvienne". Journal de la Societé des Americanistes de Paris, T, XLVI. París. Cf. BIRD, Junius. (1943). Escavation in Northern Chile. American Museum of National History. Washington.

12 HOLMES, H. George. (1951). The Centuries of Tobacco. pág. 46.

13 DE LA FUENTE, E, Zamora. Ob. Cit. 
Esta planta recibe el nombre de Nicotiana tabacum, como lo dijimos clasificada en Botánica. Proveniente del nombre de Juan Nicot, Embajador de Francia en Lisboa, que llevó este producto de las islas de Tabago a su patria y la obsequió a su Reina Catalina de Medicis: por los que se le conocía ésta con el nombre de "Yerba de la Reina". Francia autoriza su libre consumo, después de analizarla y comprobar que no era planta peligrosa. De Francia pasó su consumo a Inglaterra y se generalizó por toda Europa $^{14}$.

En honor al nombre del importador (Juan Nicot) el sabio naturalista sueco Carlos de Lineo -1707-1778- la clasifica y le da el nombre de Nicotiana tabacum. El apelativo genérico lo deriva de Nicot y el específico por haberla traído de la isla de Tabago. Esta clase de tabaco es poco cultivada, hay mejores especies y ésta pertenece a la familia de las Solanáceas y clase de las Fanerógamas ${ }^{15}$.

Las variedades son muchas, obtenidas ya por cruzamientos naturales y artificiales. La Taxonomía de este género Nicotiana es confusa y muy dilatada. Las más interesantes son la Nicotiana tabacum, Nicotiana rustica y la Nicotiana macrophylla ${ }^{16}$.

El mérito de haber introducido el tabaco en Europa es del misionero español fray Romano Pane, quien lo envió al Emperador Carlos V, implantando su cultivo en el viejo Continente. De ser así el alcaloide se hubiera llamado " $\mathrm{Pa}$ num", es decir "Panum tabacum".

Wightman W. Garner ${ }^{17}$ comenta que don Francisco Hernández de Toledo, al regresar de América a España en 1559, llevó la semilla y que fue cultivada como planta medicinal y la describió Nicolás Monardes, Médico y Naturalista de Sevilla en 1574 quien nos refiere que algunos indios de la Nueva España hacían una

14 DUDA, Pablo Luis. (1953). La industria del Tabaco en el Perú. Lima-Perú.

15 EBRO, Juan de. Ob. Cit.

16 TOWLE, Margaret A. (1961). "The Etnoboteny of precolunbian Peru". Viking Fund Publications in Antropology № 30. Washington. Cf. COMPAÑÍA RECAUDADORA DE IMPUESTOS. (1920). Cultivo del Tabaco. Lima-Perú.

17 GARNER, Wightman W. (1951). The Producction of Tobacco. Pág. 46. Cf. DE LA FUENTE, E. Zamora. Ob. Cit. pelotillas de tabaco las que puestas en el labio inferior de los dientes, les sirvan de viáticos para caminar tres o cuatro horas son molestias de hambre ni sed.

En Inglaterra la Nicotiana rústica fue introducida por Sir. Richard Grenville y el capitán Ralph Lane en 1565, procedente de Florida. Sir Francis Drake, en 1573 introduce la Nicotiana Tabacum. La "pipa" es llevada por Sir Walter Raleig y su uso era un acto de refinada elegancia. En 1600 los ingleses llevan la Nicotiana Rústica a Rusia.

En 1556 el Monge André Thevet, al regreso del Brasil a Francia es el primero en cultivarlo en su país, haciendo referencias de sus propiedades medicinales. El cardenal Próspero de Sancroce, Nuncio Apostólico en Portugal, lo introduce en Italia en 1561. Se cultivaron en los jardines de Roma y recibieron el nombre de "La Yerba de la Santa Cruz".

Durante la primera mitad del siglo XVI el uso y el cultivo de esta planta, se extendió por Bélgica y Holanda. Los portugueses lo presentaron en el Japón, Corea y Manchuria hasta llegar a China. También ellos lo introdujeron en la India.

Fueron los turcos quienes llevaron el tabaco a Grecia y posiblemente los árabes lo llevaron al África en el siglo XVII.

El uso del tabaco y su producción en escala no comercial, empieza en los Estados Unidos de Norte América, Virginia, por el año de $1612^{18}$.

En el Perú en los primeros años republicanos se establece la libertad de cultivo e industrialización de este producto. Las zonas tabacaleras fueron las tradicionales y fue complementaria a otros productos de pan llevar. Las áreas estaban circunscritas al departamento de Amazonas, Loreto, Lambayeque, Piura, Ancash, Tumbes y Cusco. La industria casera predominó, prefiriéndose la producción extranjera.

18 INFORME DEL TABACO. 1928: Estanco. Perú. 


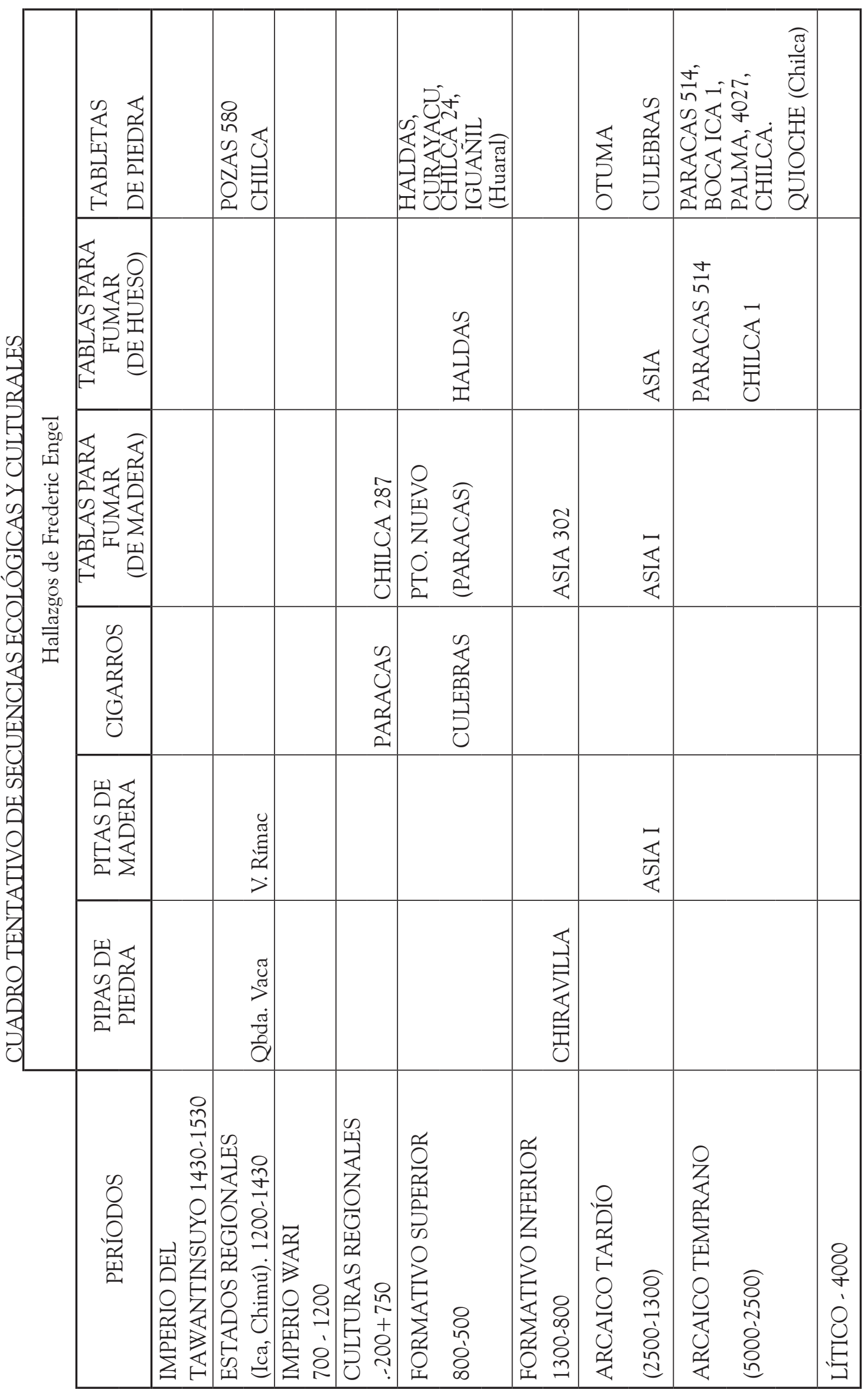

